\title{
¿FRACASÓ EL LIBERALISMO \\ EN AMÉRICA LATINA?
}

\author{
HÉCTOR ÑAUPARI*
}

Ésta es, en verdad, una pregunta encerrada en un enigma que a su vez está entremetida en un problema. Algunos sostienen que el liberalismo en América Latina ha fracasado al haber creado más pobreza y corrupción que ningún otro paradigma político en nuestra historia; otros sostienen que no fracasó el ideario, sino su aplicación; y, finalmente, están quienes sostienen que el liberalismo en realidad no ha fracasado porque nunca se aplicó. La pregunta, sin embargo, continúa allí, imbatible como un mar embravecido, y sigue desafiante, esperando que alguien la encare con objetividad, realismo y sobre todo convicción. Las líneas que siguen intentan dar una respuesta a este gordiano dilema.

El paradigma en el que baso mis disquisiciones es el viejo axioma de considerar a la libertad y la responsabilidad como conceptos integrados e inseparables. Y ello implica entre otras cosas, no distribuir —o socializar- la propia responsabilidad

(*) Abogado, ensayista y poeta. Graduado en la Facultad de Derecho y Ciencia Política de la Universidad Nacional Mayor de San Marcos, con estudios de Maestría en Derecho con mención en Derecho Civil y Comercial de la UNMSM. Diplomado en Estudios Superiores y candidato a Doctor en Derecho por la Universidad de Salamanca, España. Catedrático visitante de la Universidad Francisco Marroquín de Guatemala. Ganador del Premio Académico Internacional de Ensayo Charles S. Stillman 2001. Es autor del libro de poemas En los Sótanos del Crepúsculo (Ediciones UNMSM, 1999) y coautor de Poemas sin Limites de Velocidad, Antología Poética 1990 - 2002 (Ediciones Lord Byron, 2002). 
entre otros, sino en asumirla por todo lo hecho o dejado de hacer. De modo que, antes de buscar fantasmas a los que achacar nuestras culpas, entre los izquierdistas reciclados o los tecnócratas, examinaremos las responsabilidades que han tenido los propios liberales en este proceso. Así pues, sostengo que el liberalismo en verdad ha fracasado en América Latina, pero que este fracaso tiene distintos niveles. Arguyo además que revertir este fracaso demanda ingentes, permanentes y sobre todo comprometidas tareas, sobre todo en el ámbito de las ideas, las cuales resultan indispensables para quienes defienden las ideas de la libertad en nuestro continente. Un primer nivel de ese fracaso se encuentra en el laxo argumento de que un programa integralmente liberal en América Latina nunca se propuso y por ende, tal fracaso no existe. Se trata de un programa que comprendiese no sólo privatizar o reducir la inflación, sino sobre todo hacer del derecho una herramienta que facilite la creación de la riqueza, una profunda reforma a la justicia de nuestros países, la drástica eliminación de impuestos y la reducción de sus tasas, la extensión de la propiedad privada y su difusión democratizadora en los sectores más empobrecidos de nuestras sociedades, y una reducción de las funciones, activos, acciones y organismos del Estado, devolviéndolas a sus legítimos titulares, las gentes, y dejando como sus únicas actividades - con expresas y legítimas reservas - a la seguridad externa e interna, las relaciones internacionales con otros Estados y la administración de justicia. En suma, un programa centrado en ideas claras, con propuestas muy concretas y serias, y cuyo objetivo sea establecer y extender una revolución liberal, capitalista y popular en América Latina. Lamentablemente muchos liberales se han amparado en la débil coartada que sostiene que, como este programa nunca se propuso ni se aplicó, entonces no hemos fracasado. Una lectura más detenida nos obliga a decir que no es que no hayamos perdido, sino que no nos presentamos a la justa a la que habíamos sido convocados. Así 
pues, no perdimos porque nuestros rivales ideológicos, los socialistas y conservadores, presentaran mejores programas, o que éstos fuesen más innovadores, inteligentes o eficaces; perdimos, simplemente, porque no estuvimos allí y ni siquiera elaboramos dichas propuestas de manera integral y conjunta, sino a lo sumo parcial y de modo coyuntural. Por ende, ¿cómo nos íbamos a presentar a una competencia en la que sólo presentaríamos ideas inconexas e incompletas? ¿cómo íbamos a propender a la gran transformación de nuestras sociedades a través de la libertad sin un ideario coherente, terminado y dirigido a enfrentar resueltamente los problemas más sustanciales de los ciudadanos de a pie de nuestros países? Este desconocer como un fracaso no haber presentado ni promovido un programa integral para la libertad en América Latina es lo que más directamente ha contribuido a la derrota de los liberales en la década de los noventa. Y hay allí una responsabilidad mayor, porque no haberlo hecho ha dejado en manos de los oportunistas de siempre el camino hacia un posible progreso de nuestros países, el cual ha quedado, una vez más, truncado. Revertir ese fracaso - y presentar tal ideario- es la tarea de la década que se inicia, y deberá ser la principal prioridad de los liberales durante los años siguientes.

Por otro lado, los liberales que propugnan esta tesis - así como la de la parcialidad liberal de las reformas en su contenido o aplicación- olvidan por lo general una verdad tan grande como un templo, que es, además, el segundo nivel de este fracaso: que propugnar un programa de corte tan radical y purificador, requiere un movimiento de opinión pública - es decir, de promoción de las ideas liberales- que convenza exitosamente de sus resultados a las mayorías nacionales, que denuncie decidida y permanentemente las arbitrariedades, tropelías y sensualidades del poder, las derrote en el imaginario popular y en las creencias y mitos ideológicos de las personas, y formule los ejemplos y paradigmas para desmenuzar 
al némesis de la libertad —el poder-en tantas partes como personas existan en una república. Y un movimiento de opinión pública de estas características tiene como primera tarea enfrentar a los partidos políticos - y a sus respectivos líderes- que usaron el ideario de la libertad para permanecer en el poder - como el Partido Revolucionario Institucional de México-o que lo usaron como un maquillaje para cubrir su auténtica naturaleza - como el Partido Justicialista de Argentina- o que se coaligaron con partidos, los cuales, por su ideología y estructura son opuestos a la libertad — como el Movimiento Libertad de Perú - o que de liberal sólo tienen el nombre - como el Partido Liberal de Colombia, afiliado a la ¡Internacional Socialista!- o que, finalmente, tomaron la filosofía de la libertad en forma parcial, es decir, sólo considerando libertades económicas pero dejando deliberadamente de lado libertades más fundamentales — como los dos principales partidos de Chiledenunciándolos y descalificándolos por haber hecho con la idea de la libertad lo que Procusto hacía con sus infortunados huéspedes: mutilándolos o estirándolos según su particular y caprichoso parecer. Se trata por cierto de un movimiento de ideas y opiniones que sea leal al principio antes que al cálculo, al ideario antes que a la momentánea ventaja, al objetivo último de transformar una sociedad lastrada en una sociedad libre antes que en el pírrico triunfo que proporciona el corto plazo. Como ha señalado con acierto Jesús Huerta De Soto, el pragmatismo es el vicio más peligroso en el que puede caer un liberal (...) motivando sistemáticamente que por conseguir o mantener el poder se hayan consensuado decisiones politicas que en muchos casos eran esencialmente incoherentes con los que deberían haber sido los objetivos últimos a perseguir desde el punto de vista liberal. Y envueltos en ese pragmatismo se hallan muchos que se llaman a sí mismos «liberales», que vendieron sus talentos a los partidos, alianzas y frentes que llegaron al poder en la década de los noventa, para propiciar reformas parciales, incompletas $y$, sobre 
todo, falsas; es decir, meras coberturas para salvaguardar intereses del todo ajenos al ideario liberal.

Tales «liberales» propusieron privatizaciones que resultaron en descarados monopolios privados o de empresas públicas extranjeras; dirigieron las privatizaciones hacia artificiales mantenimientos del déficit fiscal; generaron paridades monetarias artificiales y sostenidas con las reservas nacionales antes que sujetas a la ley de la oferta y demanda; mantuvieron incólume el poder del Estado extendiendo concesiones antes que propiedades privadas plenas; generaron organismos reguladores donde ellos mismos se emplearon; y callaron cuando se usaron los dineros de las privatizaciones para actos de corrupción de medios de comunicación, políticos y empresarios, o para la propaganda y sostenimiento de los regímenes a los que sirvieron - si es que no se beneficiaron directamente de tales maniobras - como en el caso del Perú. Con ello, y merced al silencio gratuito de los muchos que, seguidores del ideario liberal, no los enfrentaron "por mantener las principales reformas intactas» se les suministraron las mejores armas a nuestros adversarios ideológicos: una «reforma liberal» que era en realidad - dicho esto con todo acierto por los colectivistasla continuación del mercantilismo de siempre por otros medios. El día de hoy, muchos de estos «liberales», proclaman a los cuatro vientos - en columnas de opinión o informes diarios de coyuntura- su adhesión, en mayor o menor grado, a los principios de la libertad, a pesar de los desarreglos cometidos cuando servían al poder. Sin embargo, ninguno de los auténticos defensores de la libertad ha salido a combatirlos resueltamente. Por esta razón, los auténticos liberales, que no nos dejamos influir por el poder, somos vergonzantes comparsas de sus desajustes al no enfrentarlos, y dejamos por nuestra omisión que tales picardías arrastren hoy por hoy el prestigio, las acciones y propuestas de todos los que nos denominamos liberales. 
Un tercer y más complejo nivel de este estropicio es de orden intelectual. Los intelectuales liberales han confundido la natural separación entre la labor intelectual y la actividad política así como la consustancial suspicacia y cuestionamiento al poder político que es propia del pensamiento liberal en su raíz más profunda, con el hecho objetivo de que la política es el último tramo del camino a fin de realizar las transformaciones necesarias para hacer más libres a nuestras sociedades, y hasta con el solo hecho de analizar y opinar sobre una estrategia política a favor de la libertad, creyendo enfáticamente que ambos temas son una y la misma cosa, cuando en realidad son dos circunstancias, enfoques, quehaceres y hechos distintos. Un intelectual liberal radical tan «químicamente puro» como Murray Rothbard señaló preclaramente en su libro La Ética de la Libertad, al exponer la relación entre la libertad y la política, que los liberales estábamos entrando en aguas inexploradas. Esto revela lo poco que los intelectuales liberales han tratado siquiera el tema, dejándose llevar más bien por sus propios temores y prejuicios. Quizás debamos llamar a este problema «el síndrome Vargas Llosa», por el cual la derrota de nuestro Escritor Mayor en las elecciones de 1990 - y en particular los extremos de inmundicia a los que la izquierda y la socialdemocracia peruanas llegaron para difamar a este prestigioso intelectual e impedir el hecho inédito en nuestra historia contemporánea de que el ideario liberal hubiese ganado las elecciones en el Perú, y acaso en nuestro continente- ha originado la decisión de la casi totalidad de intelectuales liberales en América Latina de no participar en actividad política alguna, y mucho menos partidaria.

Ahora bien, si la guerra sucia contra Mario Vargas Llosa y su posterior derrota política ha sido considerada como un detonante para extinguir todas las pretensiones de los intelectuales liberales latinoamericanos de hacer política activa, o por lo menos de analizarla según sus parámetros y paradigmas antes 
que simplemente denostarla, una razón que se invoca a menudo se encuentra en una aseveración hecha por Friedrich von Hayek al empresario inglés Anthony Fisher, de no hacer política sino más bien fundar institutos dedicados a promover la libertad, lo que llevó a este último a crear en 1955 el Institute of Economics Affairs en Inglaterra. Esta aseveración, que fue y es tomada a rajatabla y sin cesuras por los ideólogos liberales, unida a los consabidos terrores y desconfianzas que provocan a los pensadores y divulgadores de ideas participar en política, ha generado el error intelectual de considerar al ideario de la libertad como un sistema de ideas por completo ajeno al devenir político, un corpus inmaculado al cual la acción política podría pervertir y envilecer, y al cual hay que defender de los apetitos de poder y concesiones que los políticos hacen por naturaleza. Por lo tanto, para la inmensa mayoría de los intelectuales liberales, el establecimiento de sociedades libres y en tránsito seguro y claro hacia la prosperidad en América Latina dependerá exclusiva y determinantemente de la divulgación intelectual de las ideas de la libertad, pero sobre todo de que este ideario se encuentre lo más alejado posible de la política y sus actores.

En el supuesto de que la prosperidad en América Latina dependa solamente de la divulgación intelectual de las ideas de la libertad, debemos decir que los liberales en esta tarea han fracasado en toda regla. El nulo convencimiento de todos los formadores de opinión —desde los maestros más humildes hasta los más destacados líderes empresariales-sobre la validez, éxito y certeza del pensamiento liberal en todo el continente es uno entre muchísimos y claros ejemplos de que en este tema, como en los anteriormente indicados, los liberales estamos en la edad de piedra. Por lo pronto, la urgente tarea de los intelectuales liberales es convencer en forma paciente y pedagógica a la opinión pública de la eficacia, prevalencia y certeza de nuestras ideas. Y ésa es una tarea estrictamente 
intelectual a la cual los liberales se han negado rotundamente, movidos precisamente por mantener la pureza de los principios libertarios e impidiendo que éstos lleguen al gran público, justamente a través de los formadores de opinión, una tarea que el propio Hayek demandó hacer.

Y aquí queremos dejar claro que no es el objetivo de este artículo decir que es indispensable y necesario que los intelectuales liberales participen en política activa. Ésta es, en último término, una decisión exclusivamente suya. Sería precisamente lo contrario al pensamiento liberal imponer a otros un criterio o atributo que es sólo de su responsabilidad. Eso no es lo que se propone. El objetivo es dejar en evidencia que el ideario de la libertad no es puramente intelectual, sino que es además una ideología politica: tiene que ver precisamente con combatir al poder, con limitarlo y someterlo, y con considerarlo la fuente de todos los males sociales. Es reconocer el hecho innegable que el ideario de la libertad no es propiedad de unos cuantos iluminados, sino de todos quienes, habiendo escuchado el mensaje y entendido sus ejemplos, afirmaciones y conclusiones, lo apliquen en sus propios objetivos personales o institucionales. De modo que no podemos impedir que haya personas que quieran participar en política enarbolando las ideas de la libertad, o que los denostemos con acritud por hacerlo. Es, en última instancia, también una decisión en la que no podemos interferir sin que nos acusen de atentar contra la libertad de otros. Y, finalmente, si los intelectuales y divulgadores liberales llevan a cabo las tareas que les son propias - y que no han hecho en toda la década pasada ni en los primeros años de la actual- la consecuencia será que la opinión pública tienda a exigir mayores dosis de libertad y a estar vacunada contra el poder y sus abusos, y así el efecto — si se quiere, no querido ni premeditado- será que haya políticos que triunfen en las elecciones para cumplir con esas exigencias. Son ellos los que concretarán tales demandas en acciones como las de 
desactivar un Ministerio, eliminar el curso forzoso de la moneda, reducir los impuestos, abolir las aduanas o extender la propiedad privada en telecomunicaciones. La labor de los intelectuales liberales en un escenario hipotético como el descrito será el de generar las fortalezas necesarias para impedir nefastas vueltas al pasado y también para denunciar las torpezas y arbitrariedades que el poder hace cometer hasta a los espíritus más nobles. Se trata en suma de señalar la buena dirección: más libertad, más prosperidad, mayores afirmaciones de los derechos individuales.

Lo que no pueden seguir haciendo los intelectuales liberales es seguir encerrados en sus torres de marfil. Deben formar más pensadores, técnicos y divulgadores resueltos a defender nuestras ideas, deben acercar el ideario de la libertad a la gente común, deben formular propuestas que sean soluciones concretas a los problemas de las personas de a pie de nuestros países, en lugar de mantener el status quo imperante -contribuyendo en ello hasta más que los propios conservadores- por persistir en el error de mantener una pureza intelectual del liberalismo que es ajena a la sustancia de este ideario.

Hasta el día de hoy los liberales nos hemos convertido en simples y quejosos espectadores de lo que ocurre a nuestro alrededor. Por doquier nos contrariamos de las diarias tropelías del intervencionismo que nos asfixia y coarta toda posibilidad de innovación y avance empresarial; cada artículo que publicamos sobre las absurdas propuestas, leyes y acciones de parlamentos y gobiernos latinoamericanos es en verdad un recordatorio de lo poco que estamos haciendo realmente para que esa circunstancia cambie. ¿Y qué hacer? Se preguntarán muchos. Insistimos: ir a los principios. El liberalismo es una ideología política, no una diletante posición intelectual. Supone, como lo hicieron en su vida y obra Thomas Jefferson o Juan Bautista Alberdi, pensar y desarrollar los principios y combatir 
por ellos en la arena política. O en sólo esas dos primeras tareas, como lo hicieron con singular maestría en todo el siglo XX Ludwig von Mises o Friedrich von Hayek. O únicamente en acercarlas al gran público, como lo llevó a cabo con extraordinaria lucidez Frédéric Bástiat. Pero no es de ninguna manera, a nuestro juicio y como ha indicado la historia y la literatura, ser un plácido edificador de metáforas como Oscar Wilde, sino ser, como Lord Acton, quien entiende que propugnar la libertad implica defenderla permanentemente. Y permanentemente quiere decir en todo lugar y espacio. Y quiere decir, para no fracasar una vez más, desarrollar una propuesta integral, atractiva, innovadora y resuelta a favor de la libertad; generar un movimiento de ideas en la opinión pública que la enarbole y defienda; combatir a los seudo liberales que se vendieron por un plato de lentejas; divulgar en forma sostenida y con resultados el ideario liberal; pero, sobre todo, renunciar a la actitud mediocre del dandy intelectual, del francotirador de argumentos, del aristócrata del pensamiento, y vincularse resueltamente con lo llano y común de un pensamiento que provino, en esencia, del deseo inmarcesible de los pueblos por la libertad. 